\title{
Anabases
}

ANABASES Traditions et réceptions de l'Antiquité

$24 \mid 2016$

Varia

\section{William den Hollander, Josephus, the Emperors, and the City of Rome}

\section{Claude Aziza}

\section{(2) OpenEdition}

1 Journals

Édition électronique

URL : http://journals.openedition.org/anabases/5770

DOI : 10.4000/anabases. 5770

ISSN : 2256-9421

Éditeur

E.R.A.S.M.E.

\section{Édition imprimée}

Date de publication : 10 novembre 2016

Pagination : 350-351

ISSN : 1774-4296

\section{Référence électronique}

Claude Aziza, «William den Hollander, Josephus, the Emperors, and the City of Rome », Anabases [En ligne], 24 | 2016, mis en ligne le 15 novembre 2016, consulté le 24 septembre 2020. URL : http:// journals.openedition.org/anabases/5770 ; DOI : https://doi.org/10.4000/anabases.5770

Ce document a été généré automatiquement le 24 septembre 2020.

(c) Anabases 


\title{
William den Hollander, Josephus, the Emperors, and the City of Rome
}

\author{
Claude Aziza
}

\section{RÉFÉRENCE}

William den Hollander, Josephus, the Emperors, and the City of Rome, Leiden/Boston, Brill, 2014,410 p.

122 euros / isbn 978-90-04-26433-5

1 On connaît l'essentiel des relations entre Flavius Josèphe et les Flaviens, d'abord par ce que l'historien en a dit, ce qui laisse parfois des zones d'ombre que la sagacité mais aussi l'imagination des critiques ont tenté d'éclairer. L'auteur, en cinq chapitres, précédés d'une introduction et suivis d'une conclusion, dresse le portrait le plus actuel et, sans doute, le plus scientifique des rapports entre Josèphe et Rome. D'abord à la cour de Néron, puis captif de Vespasien, aux côtés de Titus lors du siège de Jérusalem, protégé par Domitien, intégré - mais dans quelle mesure ? - à la société païenne et à celle juive de la Rome des années 70 , Josèphe a pu connaître, au cours d'une longue existence dont on sait mal la fin, la difficulté d'être à la fois Juif et ami des Romains.

2 Sur le séjour de l'historien dans la Rome de Néron, on sait, au fond, peu de choses. Et c'est sans doute le chapitre le plus original de l'ouvrage. Déjà manquent dates de départ et de retour, l'hypothèse la plus vraisemblable étant qu'il est parti de Judée à l'automne 64 pour y revenir au printemps 66. Des historiens à l'imagination fertile ont même supposé qu'il avait voyagé sur le même navire que Paul, emmené en captivité à Rome. À tout le moins qu'il l'avait rencontré dans la Ville. Rien de cela n'est indiqué nulle part. D'ailleurs Josèphe ne semble pas connaître les premiers groupes judéo-chrétiens. Par ailleurs, on ignore la nature de ce voyage, mission officielle ou séjour privé. Il ne semble pas avoir rencontré Néron, à coup sûr Poppée dont on sait qu'elle était "judaïsante ", ce terme recouvrant des réalités diverses. Car autour de Poppée gravitent des Juifs dont le plus connu est le mime Aliturus. 
Sur les liens de Josèphe avec les Flaviens, les choses sont plus claires. Prisonnier de Vespasien, qui n'est pas encore empereur, chargé de chaînes, il lui prédit, dans un mélange d'intuition et de charlatanisme, le trône impérial. Quoi d'étonnant que Vespasien, devenu empereur, le tienne désormais en haute estime? Dès lors, Josèphe est dans le camp de Titus devant Jérusalem, où sa propre famille compte parmi les assiégés. D'ailleurs, il n'est pas le seul à s'être rallié - par opportunisme, nécessité ou conviction - aux Romains. Agrippa II, accompagné de sa sœur Bérénice, est là aussi avec ses troupes. Quel a été alors le rôle exact de Josèphe ? Simple captif, devenu allié, historiographe chargé de prendre des notes sur le siège ou contact obligé avec les fuyards de Jérusalem dont les renseignements sont précieux? Quoi qu'il en soit, il reviendra à Rome avec Titus chargé d'honneurs (et de richesses ?).

La mort brutale et prématurée de son protecteur, le départ forcé de Bérénice, avec qui il semble avoir entretenu de bons rapports, l'amènent à se retourner vers Domitien, qu'il n'a pas connu durant la guerre, mais qui le conforte dans son rôle de protégé et d'historien. Dans ces conditions, jusqu'où a-t-il pu garder son identité judéenne? Surtout à un moment où le nouvel empereur a imposé aux vaincus et à tous les Juifs de l'Empire un impôt spécifique, le fiscus iudaïcus.

5 Pour répondre à cette question complexe, c'est le dernier chapitre qu'il faut consulter, celui des relations de Josèphe avec ses coreligionnaires de Rome. L'historien a-t-il vécu isolé, en butte à l'hostilité de ceux qui le prennent - déjà ! - pour un « collaborateur »? Non, si l'on en croit un passage (3, 9, 1-2) de l'Histoire ecclésiastique d'Eusèbe. A-t-il fréquenté un cercle littéraire? A-t-il pu lire des fragments de son œuvre? Il semble logique de penser qu'il a conservé de bonnes relations avec les Hérodiens, notamment Agrippa II. Logique aussi d'imaginer qu'il a conservé des liens avec les généraux qui accompagnaient Titus, au moins avec Tiberius Julius Alexander, alexandrin, juif apostat, neveu de Philon le Juif et promis aux plus hautes fonctions en Égypte et en Judée.

6 Passionnantes questions qu'avec une érudition extraordinaire, certifiée par d'innombrables notes (qui, il faut bien l'avouer, alourdissent parfois le propos) et par une abondante bibliographie, l'auteur tente de résoudre, en examinant toutes les hypothèses et en tentant de se frayer un chemin dans ce maquis touffu, qui s'est élevé depuis des siècles, sur la personnalité et le rôle de Josèphe. On ne peut que lui en être reconnaissant.

\section{AUTEURS}

\section{CLAUDE AZIZA}

Université de la Sorbonne Nouvelle - Paris 3

claude.aziza@laposte.net 